\title{
A Case of Parietooccipital Subdural Empyema After Spinal Anesthesia
}

\author{
(D) Tarkan Mıngır ${ }^{1}$, (D) Betül Sinoğlu1 ${ }^{1}$, (D) Cengiz Polat ${ }^{1}$, (D) Ahmet Yasin Ayvuz², (1D Namigar Turgut ${ }^{1}$ \\ 1 University of Health Sciences Turkey, Prof. Dr. Cemil Taşçığlu City Hospital, Clinic of Anesthesiology and Reanimation, Istanbul, Turkey \\ 2 University of Health Sciences Turkey, Prof. Dr. Cemil Taşçığlu City Hospital, Clinic of Neurosurgery, Istanbul, Turkey
}

\section{Abstract}

Subdural empyema represents a loculated suppuration between the dura and the arachnoid. It has been described either intracranially or in the spinal canal and the latter localization is quite rare. It is a rare but serious disease with a decreasing mortality rate but rather common neurological sequelae. A high index of suspicion along with its typical clinical presentation such as headache, seizures, or focal neurologic signs can lead to early diagnosis so that effective treatment can be administered as soon as possible. Advances in the diagnosis and treatment of brain abscess and subdural empyema with neuroimaging techniques such as computerized tomography, magnetic resonance (MR) imaging, MR spectroscopy, the availability of new antimicrobials, and the development of novel surgical techniques have significantly contributed to the decreased morbidity and mortality associated these infections. Morbidity and mortality in intracranial and spinal subdural empyema are directly associated with the delay in administration of treatment. Both conditions should, thus, be treated with great urgency. In this case, we aimed to underline the possibility of intracranial subdural empyema occurence after spinal anaesthesia.

Keywords: Subdural empyema, spinal anaesthesia, fever, headache

\section{INTRODUCTION}

Subdural empyema is the accumulation of pus in the potential gap between the dura mater and the arachnoid membrane, and the most common cause is meningitis in children and sinusitis in adults (1-4). Like cranial epidural abscesses, most of the cranial subdural empyema is related to paranal sinusitis, otitis media, trauma and neurosurgical interventions. 50\% of cranial subdural empyema cases can be detected with osteomyelitis or epidural abscess $(5,6)$.

It constitutes $15-25 \%$ of all intracranial infections (1). Rapid diagnosis, surgical drainage and appropriate antibiotic treatment reduce mortality (7). The most common clinical triad is fever, neurological deficit and sinusitis. The findings such as headache, mental state change, fever, focal neurological deficit, vomiting, neck stiffness ease the diagnosis (2). In epidural abscesses, symptoms related to mass effect are in the foreground, while the patient may be in a toxic picture in subdural empyema. Clinically, it may be difficult to differentiate it from the brain abscess. Computed tomography (CT) or magnetic resonance (MR) are the methods to be chosen in the diagnosis $(5,6)$. While complete recovery can be achieved with the proper treatment, there is high mortality or permanent neurological damage in case of delayed treatment or in untreated cases (1). The fact that the application findings are nonspecific in the early period, despite the advanced imaging methods, cause difficulties in diagnosis occasionally. Spinal subdural empyema is extremely rare. In treatment, empyema should be evacuated and antibiotic treatment should be administered, and antibiotic treatment should be continued for at least 3 weeks $(5,6)$.

Here we present a subdural empyema case, a rare complication of spinal anesthesia.

Phone: +90 5333607659 E-mail: namigarturgut@gmail.com ORCID ID: orcid.org/0000-0003-0252-3377

Cite this article as: Mıngır T, Sinoğlu B, Polat C, Ayvuz AY, Turgut N. A Case of Parietooccipital Subdural Empyema After Spinal Anesthesia. Eur Arch Med Res 2020;36(3):222-5

${ }^{\circ}$ Copyright 2020 by the University of Health Sciences Turkey, Prof. Dr. Cemil Taş̧ıŏlu City Hospital European Archives of Medical Research published by Galenos Publishing House. 


\section{CASE PRESENTATION}

An emergency caesarean section was performed due to acute fetal distress with spinal anesthesia in an eighteen-year-old, of ASA I physical group patient, whose consent was obtained, and is in the physical group, while there is not a feature in the anamnesis and laboratory tests. The patient had headaches occasionally, applied to several health centers, and no pathology was detected in the examinations. The patient had a fever, opened wound in the caesarean area, formication and numbness in the left arm and leg, it was evaluated as postpartum fever and antibiotherapy was initiated. In the neurology consultation of the patient whose complaints continue; general condition is good, conscious, direct and indirect light pupil reflex bilateral $+/+$, left upper extremity muscle strength $-5 / 5$, four extremity deep tendon reflexes were found normoactive. In cranial CT; minimal effusion at the subdural distance in the left occipital region and widespread edema in the left hemisphere were observed and acetylsalicylic acid $100 \mathrm{mg}$ and low molecular weight heparin 0.6 were started primarily by considering venous thrombosis (Figure 1). The patient's complaints continued, in contrast cranial MR taken 2 days later; left hemispheric sulcus were cleaned, cerebral parenchyma has edema, $13 \mathrm{~mm}$ depth and 36x59 mm intense collection (empyema), contrasting at the subdural distance at left parietooccipital region, fluid collection in the sphenoid sinus, meningial and meningeal inflammation in left cerebral hemisphere, and accompanying cerebritis findings were detected.

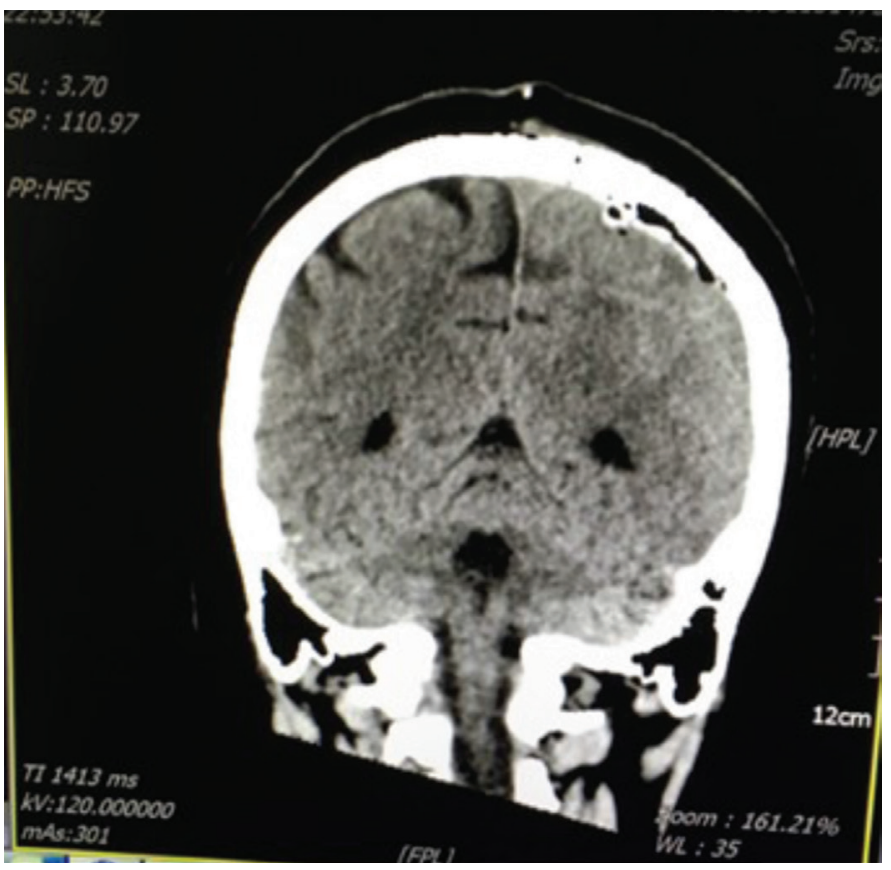

Figure 1. Cranial CT; minimal effusion at subdural distance in the left occipital region and widespread edema in the left hemisphere CT: Computerized tomography
(Figure 2). After the emergency operation was planned, 2 burr holes opened following the control of bleeding in prone position under general anesthesia. Purulent material was evacuated and sent to the laboratory. Hemostasis was achieved, duraplasty was performed and tisseel was applied. One hemovac drain was placed at the epidural distance, the layers were closed proper to their anatomy (Figure 3). No postoperative complications developed, no transfusion performed. Since our case was initially evaluated as postpartum fever and antibiotherapy was initiated, there was no growth in blood, wound culture, and urine culture. Ceftriaxone disodium and metranidazole treatment were initiated with the recommendation of the infection committee. Infection parameters decreased in the following laboratory tests (C-reactive protein: 12, white blood cell: 7.32, hemoglobin: 11.3, procalcitonin: 0.03). Normal findings were detected in the noncontrast CT (Figure 4) in the early postoperative and 1st week, and then the patient, whose antibiotherapy continued, was discharged with healing.

\section{DISCUSSION}

In the presented case with the central nervous system infection, the cause of headache could not be found since there were no clinical and physical examination findings. With the precence of

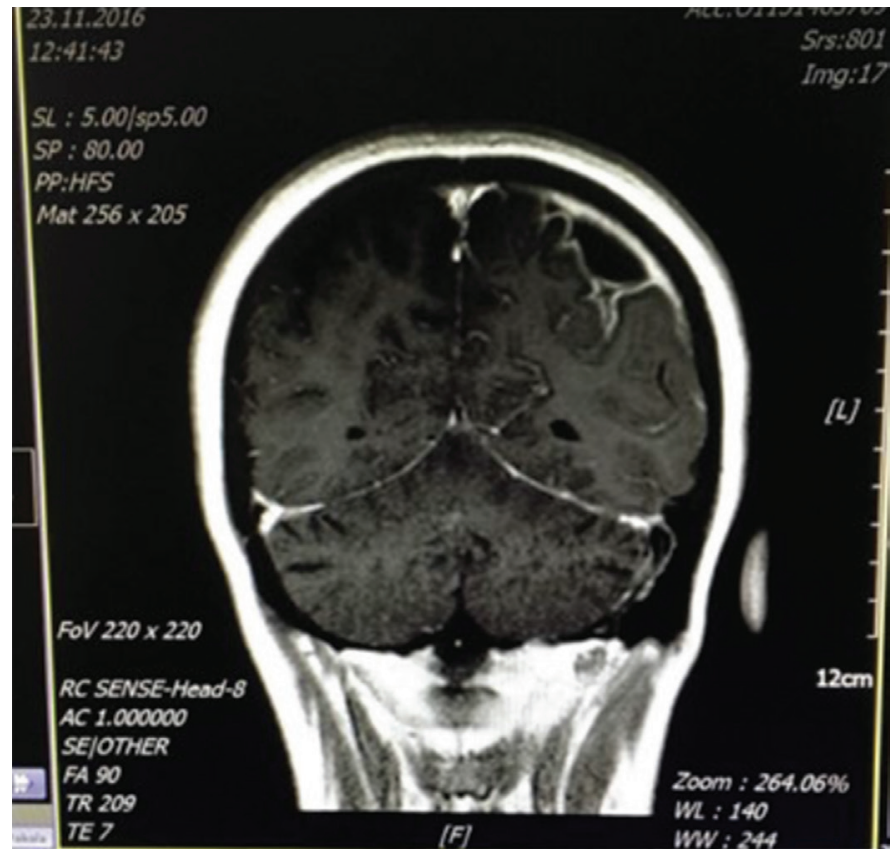

Figure 2. Cranial MR with contrast; left hemispheric sulcus deleted, cerebral parenchyma is edematous, $13 \mathrm{~mm}$ depth 36x59 mm intensive collection of contents involvement in left parietooxypital level subdural distance, sphenoid sinus fluid collection, menengial and menengial inflammation in the left cerebral hemisphere and accompanying cerebral findings

MR: Magnetic resonance 
fever, the other factors that might cause fever were evaluated and it was diagnosed as postpartum fever and antibiotherapy was initiated. Central nervous system imaging was made and subdural empyema diagnosis was made due to severe headache, fever complaints in the application, and the first motor neuron findings in the neurological examination in our hospital.

Subdural empyema is a locular infection of the meninges between the dura and the arachnoid and may develop in the intracranial or spinal canal $(1,2)$. Intracranial subdural empyema is often a complication of sinusitis or less frequently otitis or neurosurgical interventions $(8,9)$. In the literature, subdural empyema due to spinal anesthesia only is limited to a few cases (10).

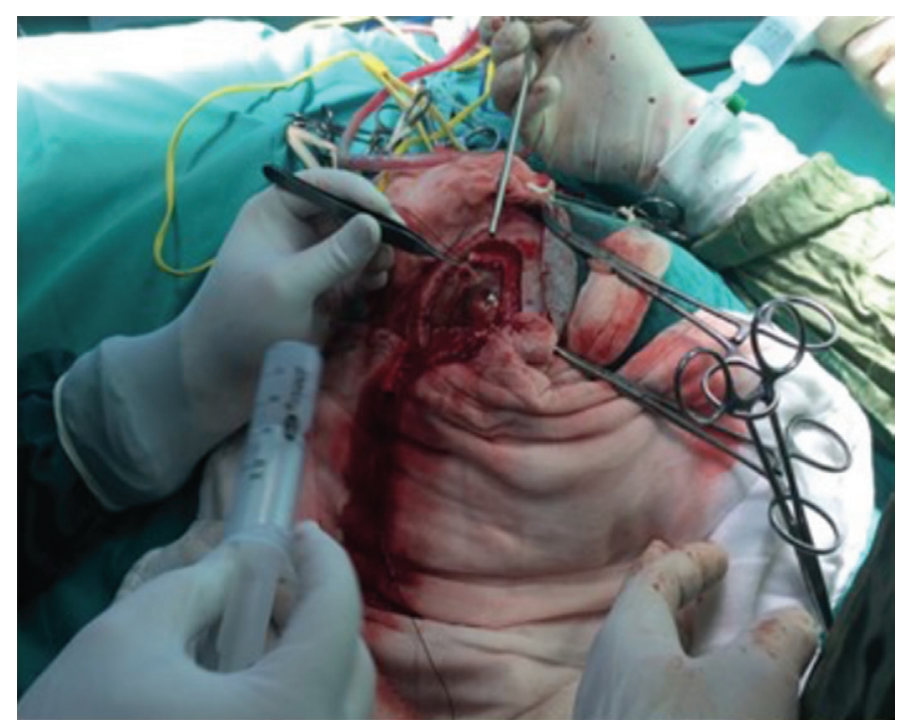

Figure 3. Intraoperative empyema discharge

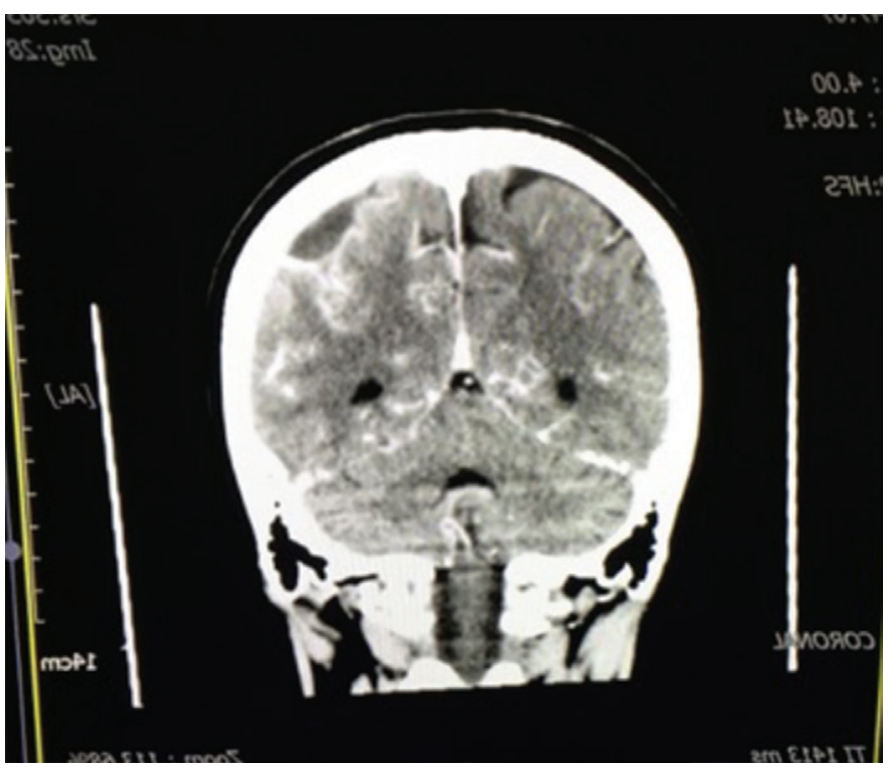

Figure 4. Non-contrast CT in early postoperative period CT: Computerized tomography
In our patient, fluid collection was observed in the sphenoid sinus in MR. The developing subdural empyema may also originate from sinusitis, but the development of the clinical picture after spinal anesthesia, the initiation of antibiotherapy with a preliminary diagnosis of wound infection, worsening of findings and the diagnosis and treatment of sinus thrombosis complicated the case.

Recent epidemiological series in Europe suggest that the frequency of infectious complications associated with neuroaxial techniques may increase (11). The most common organisms in intracranial subdural empyema are anaerobic and microaerophilic streptococci (8). In the literature, isolation of rare microorganisms such as Mycoplasma hominis isolation from subdural empyema in culture biopsy material has also been observed. In the case that Delgado Tapia et al. (12) presented: in the 32-year-old patient who experienced throbbing-style headache 48 hours after cesarean delivery under spinal anesthesia, abscess was detected in the abdominal wall with worsening headache on the fifth day of the operation; despite antibiotic treatment, when fever and headache persisted, as in our case, subdural empyema was detected in cranial MR imaging and drainage was performed twice with emergency surgery. After the combination of surgery and antibiotic therapy, the patient was completely cured.

The diagnostic procedure selected for intracranial and spinal subdural empyema is CT, MR. CT scan may not identify intracranial subdural amps that can be detected by MR (13). As a matter of fact, venous thrombosis was considered primarily with CT findings in our case. In almost all cases of intracranial or spinal subdural empyema, rapid surgical drainage and antibiotic treatment are required. Pus in the empyema should always be sent for aerobic culture as well as anaerobic. Since intracranial subdural empyema may contain multiple organisms, temporary antibiotic treatment of intracranial subdural empyema, in which the organism is unknown, should be directed to Staphylococcus aureus, microaerophilic and anaerobic streptococci and gram negative organisms $(1,14)$. Antibiotics; naphsilin, oxacillin or vancomycin; + third generation cephalosporin; it should contain + metronidazole. Temporary antibiotic treatment of spinal subdural empyema should be directed to S. aureus and streptococci and should include nafsilin, oxacillin or vancomycin (15). Morbidity and mortality in intracranial and spinal subdural empyema are directly related to the delay in planning treatment. Therefore, both conditions must be treated with urgency $(1,16$ 19). Since our case was initially evaluated as postpartum fever and antibiotherapy was initiated, there was no reproduction in 
cultures, an emergency operation was performed as soon as the diagnosis was made and the abscess was evacuated. Infection parameters decreased in the following laboratory tests.

\section{CONCLUSION}

As a result; in case of prolonged headache, fever, focal neurological finding after spinal anesthesia, the problem should be considered as it is more serious than expected and the focus of infection may be the central nervous system, empirical antibiotic treatment should not be initiated before the cause of the fever is fully clarified and careful neurological examination and radiological examination should be performed.

\section{Ethics}

Informed Consent: Patient consent was obtained.

Peer-review: Externally peer-reviewed.

\section{Authorship Contributions}

Surgical and Medical Practices: T.M., B.S., C.P., A.Y.A., Concept: T.M., A.Y.A., N.T., Design: T.M., N.T., Data Collection or Processing: B.S., C.P., A.Y.A., Analysis or Interpretation: T.M., A.Y.A., N.T., Literature Search: T.M., B.S., C.P., A.Y.A., Writing: T.M., A.Y.A., N.T.

Conflict of Interest: No conflict of interest was declared by the authors.

Financial Disclosure: The authors declared that this study received no financial support.

\section{REFERENCES}

1. Kaplan T, Kuytu T, Tașkapılıoğlu MÖ, Kocaeli H, Korfalı E, Bekar A. Subdural Ampiyemlerin 20 Yıllık Retrospektif Analizi. Uludağ Üniversitesi Tıp Fakültesi Dergisi 2010;36:61-3.

2. Gençpınar P, Bektaş F, Aydın A, Duman M. A Rare Cause of Fever: Subdural Empyema. The Journal of Pediatric Research 2014;1:155-7.

3. Osborn MK, Steinberg JP. Subdural empyema and other suppurative complications of paranasal sinusitis. Lancet Infect Dis 2007;7:62-7.
4. Arifianto MR, Ma'ruf AZ, Ibrahim A, Bajamal AH. Interhemispheric and Infratentorial Subdural Empyema with Preseptal Cellulitis as Complications of Sinusitis: A Case Report. Pediatr Neurosurg 2018;53:128-33.

5. Calfee DP, Wispelwey B. Brain Abscess, Subdural Empyema, and Intracranial Epidural Abscess. Curr Infect Dis Rep 1999;1:166-71.

6. Dill SR, Cobbs CG, McDonald CK. Subdural empyema: analysis of 32 cases and review. Clin Infect Dis 1995;20:372-86.

7. Hageman AT, Gabreëls FJ, De Coo IF, Merx JL. Subduraal empyeem. Het belang van snelle herkenning [Subdural empyema. The importance of rapid diagnosis]. Tijdschr Kindergeneeskd 1991;59:210-2.

8. Greenlee JE. Subdural Empyema. Curr Treat Options Neurol 2003;5:1322.

9. Steffen H, Vogel S, Planitzer J. Isolierte subdurale Parafalxempyeme als Komplikation paranasaler Sinusitiden [Isolated subdural parafalx empyema as a complication of paranasal sinusitis]. Z Arztl Fortbild (Jena) 1985;79:881-3.

10. Beland B, Prien T, Van Aken H. Spinal and regional anesthesia in bacteremia. Anaesthesist 1997;46:536-47.

11. Horlocker TT, Wedel DJ. Infectious complications of regional anesthesia. Best Pract Res Clin Anaesthesiol 2008;22:451-75.

12. Delgado Tapia JA, Galera López J, Santiago Martín J, Galdo Abadín JR, Quirante Pizarro A, Cánovas Fernández E, et al. Subdural empyema due to Mycoplasma hominis after a cesarean section under spinal anesthesia. Rev Esp Anestesiol Reanim 2005;52:239-42.

13. Bernardini GL. Diagnosis and management of brain abscess and subdural empyema.Curr Neurol Neurosci Rep 2004;4:448-56.

14. Kielian T. Immunopathogenesis of brain abscess. J Neuroinflammation 2004;1:16.

15. Agrawal A, Timothy J, Pandit L, Shetty L, Shetty JP. Review of Subdural Empyema and Its Management. Infectious Diseases in Clinical Practice 2007:15:3.

16. De Bonis P, Anile C, Pompucci A, Labonia M, Lucantoni C, Mangiola A Cranial and spinal subdural empyema. Br J Neurosurg 2009;23:335-40.

17. Brennan MR. Subdural empyema. Am Fam Physician 1995;51:157-62.

18. Kalaycý M, Cadavi F, Altunkaya H, Gül S, Ackgöz B. Subdural empyema due to spinal anesthesia. Acta Anaesthesiol Scand 2005;49:426.

19. Suthar R, Sankhyan N. Bacterial Infections of the Central Nervous System. Indian J Pediatr 2019;86:60-9. 